\title{
FELIZ DAQUELE QUE ARRANJA UM BOM EMPREGO: TRAJETÓRIAS GERACIONAIS NO TRABALHO E EDUCAÇÃO DE FAMÍLIAS SERGIPANAS EM SANTOS ${ }^{1}$
}

\author{
Danilo Alves da Conceiçãoº
}

- Enviado em 15/04/2016

- Aprovado em 20/05/2016

\section{RESUMO}

Tendo o porto como importante atividade econômica e palco fundamental da chegada das grandes levas de imigrantes no Brasil no início do século passado, a cidade de Santos tem o fenômeno migratório como elemento inerente à sua história. Dentre as mais variadas origens que compõem a população santista, destaca-se a presença maciça de migrantes nordestinos oriundos do Estado de Sergipe. A pesquisa em desenvolvimento do qual este artigo é um desdobramento, tem como objetivo geral investigar as transformações nas trajetórias ocupacionais e de escolaridade de migrantes oriundos do Estado de Sergipe residentes na cidade de Santos. Proponho a partir da trajetória de uma família de migrantes sergipanos composta por três gerações uma reflexão acerca do fluxo migratório entre Santos e o município sergipano de Macambira. Posteriormente busco compreender através dos relatos e da contribuição teórica de Pierre Bourdieu, Richard Sennett entre outros, como as categorias trabalho e educação se modificam, relacionam ou não, de uma geração para outra e qual o papel desempenhado pela unidade familiar neste processo.

Palavras-chave: Migração. Trajetórias geracionais. Educação. Trabalho.

\section{O como, o quando, o onde e o por quêe}

A pesquisa que subsidia esse artigo encontra-se em desenvolvimento e tem como questão problema compreender de que forma as trajetórias educacionais e ocupacionais associam-se em cada uma das gerações de famílias migrantes sergipanas aqui estudadas e que são residentes na cidade de Santos. As primeiras verificações apontam para a hipótese de que o acesso à educação

\footnotetext{
${ }^{1}$ Uma versão preliminar desse trabalho foi apresentada no GT1: INSTITUIÇÕES E PODER: PARENTESCOS E GENEALOGIAS do VII Seminário Nacional de Sociologia e Política da UFPR realizado de 11 a 13 de maio de 2016 em Curitiba.

${ }^{2}$ Mestrando em Ciências Humanas e Sociais pela Universidade Federal do Abc (UFABC). Endereço eletrônico: daniloalvesfilo@gmail.com
} 
avançou nas segundas e terceiras gerações, contudo as escolhas educacionais por vezes estão sempre subordinadas a uma necessidade de rápida inserção no mercado de trabalho formal.

O tema e a problemática proposta são frutos da reflexão acerca de minha própria trajetória familiar e também da vivência como docente em escolas da Baixada Santista. Sou neto de sergipanos e desde a infância convivi com vizinhos, amigos e conhecidos de minha família que em sua grande maioria eram conterrâneos do Sergipe. A percepção da existência de uma grande comunidade não apenas nordestina ${ }^{3}$, mas oriunda especificamente do Estado de Sergipe se consolida em minha percepção quando já como docente percebo na grande maioria do meu alunado especialmente das escolas públicas que trabalhei na cidade de Santos e região, origem e trajetórias muito similares à de minha família.

A íntima relação que possuo com o objeto de estudo facilita o acesso e a disposição das famílias em contribuir com seus relatos para a pesquisa. Grande parte dos entrevistados até então, assim como no presente caso são amigos de minha família ou familiares e conhecidos de alunos e ex-alunos.

A família que é apresentada e subsidia a discussão realizada neste trabalho é oriunda da pequena Macambira, cidade situada na mesorregião do agreste sergipano a 74 quilômetros da capital Aracaju, com uma população de aproximadamente 6400 pessoas. Santos por sua vez é o maior município da Baixada Santista ${ }^{4}$ com aproximadamente 419 mil habitantes ${ }^{5}$. O Morro do Pacheco, local de residência fica situado na região do centro antigo de Santos, próximo da área portuária. No início do século passado era povoado por imigrantes portugueses em grande parte vindos da Ilha da Madeira, no entanto a partir da década de 1940 começou a ser densamente povoado por migrantes nordestinos (SANTOS, 2011).

\footnotetext{
3 “A Baixada Santista vai ser, junto com a Grande São Paulo, a região paulista que mais atraiu migrantes nordestinos. Até os anos de 1940 eles vinham em busca do trabalho no porto. Nos anos de 1950, o polo industrial de Cubatão juntouse ao porto como principal atrativo para os migrantes, que vêm principalmente de Sergipe, Bahia e Pernambuco para trabalhar nas obras de implementação e ampliação das zonas industriais. A principio, os migrantes ocupam os morros e a zona noroeste santistas. Mas em fim dos anos 1960, esgota-se, em Santos, a oferta de terrenos baratos para abrigar essa população pobre que chega cada vez em maior número, ocorrendo, então, a urbanização de áreas antes desertas na vizinha São Vicente e nos Bairros da Bocaína e Itapema, unidos depois para formar o atual Distrito de Vicente de Carvalho no Guarujá" (PIMENTA, 2002, p.78).
}

${ }^{4}$ Região metropolitana litorânea do Estado de São Paulo formada além de Santos pelos municípios de São Vicente, Praia Grande, Cubatão, Guarujá, Bertioga, Mongaguá, Itanhaém e Peruíbe. Sua população gira em torno de 1,6 milhões de pessoas,

${ }^{5}$ Dados extraídos do Censo Demográfico 2010. 
Os relatos são provenientes de entrevistas semi-estruturadas realizadas com Luiz e seu filho Antonio $^{6}$, que foram em todas as ocasiões entrevistados conjuntamente. Fica latente ao longo do texto a assimetria dos relatos entre os dois, bem como a ausência dos relatos das esposas e da terceira geração. Isto se dá devido à resistência que venho enfrentando por parte de ambos em conseguir a permissão para o acesso ao restante da família.

\section{Trabalho no campo, o não acesso à educação e a migração na primeira geração}

Seu Luiz tem 68 anos e nasceu na cidade de Macambira em Sergipe. Trabalhava junto com a família como meeiro arrendando terras de fazendeiros locais e cultivando milho, mandioca e algodão, ficando com uma pequena parte da colheita para o próprio consumo e venda, que de acordo com suas palavras, mal dava para sobreviver. Cita que certa vez tentou convencer um dos fazendeiros dos quais arrendava terra a deixá-lo criar um pasto com umas "vaquinhas" pra incrementar a sua renda, mas este não aceitou a proposta, pois queria "sempre ficar com tudo".

As características e dificuldades do trabalho no campo apresentadas por ele são similares aos apresentados no trabalho de Menezes (1985) ao analisar as condições de reprodução dos trabalhadores rurais no sertão paraibano. Em seu estudo discorre sobre a parceria, modalidade em que os camponeses faziam uso de porções de terras de grandes proprietários em troca de um pagamento em forma de porcentagem da produção. A parceria ocorria de duas formas, com o trabalhador morando de favor na terra em que trabalhava, ou simplesmente alugando-a como no caso de Luiz e sua família. Sobre as diferenças entre o morador e o rendeiro,

[...] o rendeiro não é completamente autônomo, o proprietário diz o que plantar, como deve ser plantado. O controle do rendeiro, por parte do patrão, se dá mais ao nível da produtividade, de forma a assegurar o pagamento da renda pelo preço mais alto possível. O patrão controla as atividades do morador num nível muito maior, porém tem determinadas obrigações com o morador. $\mathrm{O}$ morador está preso a uma relação pessoal e direta com o patrão, que assume um caráter moral muito forte. Muitas vezes ele enxerga a exploração, porém é incapaz de se colocar contra o patrão, pois isto significaria traição. [...] O rendeiro se sente mais livre para "escolher" o patrão. É mais livre na determinação do seu modo de vida, modo de pensar, sua consciência, sua expressão de voto (MENEZES, 1985, p.76).

Mesmo não sofrendo do controle exercido pelos grandes proprietários como no caso dos moradores apresentada por Menezes (1985), a limitação existente em manusear a terra alugada é

\footnotetext{
${ }^{6} \mathrm{~A}$ identidade dos entrevistados é preservada por meio do uso de nomes fictícios
} 
compreendida por Luiz como elemento que obstrui sua liberdade e possibilidade de sobrevivência em sua terra natal.

Ele é analfabeto, tentou estudar em sua terra natal, mas justifica que era um menino bastante briguento e as professoras não o toleravam, assim logo cedo desistiu de estudar. Pergunto se ele não teve interesse de retomar os estudos em Santos, ele responde que a sua cabeça não prestava mais para isso e esta percepção se mostrava verdadeira quando alguns companheiros de trabalho voltavam ao estudo e sempre desistiam devido ao cansaço e a dificuldade de acompanhar as aulas. Desde o primeiro contato estabelecido com Luiz, este se apresentou e também era citado por seu filho Antônio como "sem cultura" e que em nada poderia contribuir com minha pesquisa. "Bruto" e "sem cultura" são termos que apareceriam corriqueiramente em nossas conversas.

Por que Luiz e seu filho creditam a uma espécie de brutalidade naturalizada e não as condições objetivas o motivo de seu baixo grau de escolarização? A perspectiva praxiológica ${ }^{7}$ do conhecimento proposta por Bourdieu (1983) é um dispositivo teórico que auxilia em uma possível interpretação deste fato. O habitus ${ }^{8}$, conceito central na sociologia bourdieusiana, é produto das relações sociais e assegura a reprodução das mesmas estruturas objetivas que o engendram. Ele não se aplica somente à interiorização de valores e normas, mas também a esquemas classificatórios que são anteriores às representações sociais e que presidem a escolha e consequentemente à ação, sem necessariamente reduzi-la a uma reprodução mecânica (BOURDIEU, 2004).

É a partir dele que são construídos princípios de distinção e as mais variadas práticas, do que comer até como vestir-se. O habitus é uma espécie de história das condições objetivas corporificadas pelos agentes e esquecida como tal, que assegura e legitima relações de dominação e provém no caso explicitado de Antônio e seu pai uma visão dotada de violência simbólica sobre suas trajetórias (BOURDIEU 2011).

\footnotetext{
${ }^{7} \mathrm{O}$ conhecimento praxiológico entende como falsa a dicotomia subjetivismo/objetivismo e percebe o real como uma síntese dialética entre estruturas objetivas socialmente construídas que se atualizam enquanto disposições nos agentes, deste modo, "o duplo processo de interiorização da exterioridade e de exteriorização da interioridade" (BOURDIEU, 1983, p.47).

8 “.... [istemas de disposições duráveis, estruturas estruturadas predispostas a funcionar como estruturas estruturantes, isto é, como princípio gerador e estruturador das práticas e das representações que podem ser objetivamente "reguladas" e "regulares" sem ser o produto da obediência a regras, objetivamente adaptadas a seu fim sem supor a intenção consciente dos fins e o domínio expresso das operações necessárias para atingi-los e coletivamente orquestradas, sem ser o produto da ação organizadora de um agente" (BOURDIEU, 1983, p.61).
} 


\subsection{A triste partida}

Luiz saiu de Macambira rumo a Santos aos 27 anos de idade, foi o primeiro de sua família a partir atrás de uma melhora, deixando para trás seus pais e dez irmãos, além de sua esposa e filho. Além deste filho sua esposa tivera também outras duas filhas que faleceram precocemente, uma com 17 dias vítima de algum tipo de subnutrição e a outra ainda no período de gestação devido a complicações e a falta dos devidos cuidados médicos. Os pais de Luiz eram veementemente contra sua partida, afirmando que este era bruto e ignorante e que não iria se adaptar a cidade grande. Ele afirma que lembra com muita vivacidade dos pais aos prantos no dia de sua partida, mas que mesmo assim não desistiu uma vez que não via nenhuma perspectiva em manter-se ali.

Sua vinda foi incentivada por um cunhado que a época residia em Santos e afiançava a existência da abundância de empregos mesmo para aqueles que eram "sem cultura". As impressões de seu cunhado se somavam as outras histórias e boatos que existiam sobre a cidade desde a infância. É latente em sua fala o peso que Santos exercia no imaginário dos que permaneciam em Macambira e o elemento catalisador que se transmuta nos símbolos associados ao "sucesso" dos que retornam e nas representações sobre a cidade.

Apesar das dificuldades que posteriormente Luiz atestara ao se estabelecer no Sudeste, a realidade era retrabalhada de forma efêmera quando retratada pela grande maioria que retornava a terra natal. Tal característica aparece em outros estudos acerca de fluxos migratórios como no de Pais (2006) sobre imigrantes romenos estabelecidos em Portugal e na obra de Sayad, com o depoimento de argelinos que imigraram para a França.

Não, nunca nos explicam a França como ela é antes que a conheçamos. A gente os vê gastar esse dinheiro sem cuidar; eles estão bonitos, estão gordos. E, quando falam, o que dizem? Eles falam de seu trabalho. Quando dizem: "Faço um trabalho difícil", a gente os admira... Se suspeitamos que estão mentindo, é quando se vangloriam de fazer um trabalho difícil, um trabalho duro; o trabalho é sempre duro, é preciso ser forte para fazê-lo, isso quer dizer que eles ganham muito dinheiro. É isso que a gente entende quando não vimos com nossos próprios olhos [...] De resto, ninguém fala (SAYAD, 1998. p.36).

Luiz veio para Santos no ano de 1975 e durante os primeiros meses morou com um primo de sua esposa. A residência era um quarto e banheiro localizado no Morro dividido entre ele, o primo de sua esposa e sua mulher, o filho deles recém nascido e um conhecido. Pouco tempo depois foi dividir com outros dois companheiros de trabalho um quarto e banheiro também localizado no Morro. As redes familiares se mostram como um elemento crucial tanto no processo de migração quanto em seu estabelecimento. A importância das redes sociais e familiares é destacada por Rocha Trindade (1995), que compreende que além dos contextos macroscópicos e estruturais, são tais 
redes que, a níveis microscópicos são decisivas nos processos migratórios, uma vez que é a partir delas que se mobilizam a obtenção dos agentes a determinados recursos, como assistência e informação.

Muito mais do que o mero deslocamento de um dado grupo de pessoas em um espaço físico, devido a questões estruturais macro, como de ordem econômica ou de conflitos territoriais, o fenômeno migratório, se constitui em uma série de tensões e implicações subjetivas dos sujeitos que se locomovem. Não obstante, dentre as várias conceituações deste fenômeno nas ciências sociais, destaco a percepção de Sayad (1998), que afirma ser a imigração um fato social total e completo. Completo porque deve ser analisado de forma interdisciplinar, na convergência e relação de várias áreas das ciências sociais. Total por se constituir entre aspectos estruturais e motivações subjetivas dos sujeitos migrantes.

\section{3. "Saí de um inferno e entrei no outro"}

Poucos dias após sua chegada Luiz conseguiu seu primeiro emprego, na Companhia Usinas Nacionais, fabricante do Açúcar Pérola como ajudante geral, ou nos de dizeres de Luiz, como "pinhão". A maioria dos trabalhadores da Usina era de origem nordestina, entre os quais grande parte eram sergipanos. O trabalho era extremamente pesado. Sua rotina era composta por mais de 12 horas de trabalho por dia, entrava às 6 da manhã e o horário de saída era às 18 horas, porém devido ao salário extremamente baixo era praxe a realização de diárias e de horas extras, e assim a jornada que se iniciava às 6 da manhã se alongava até às 21 horas para no dia seguinte voltar novamente às seis. Ele conta que demorou a se habituar ao ritmo do trabalho, sua sensação era a de "ter saído de um inferno e entrado em outro", tinha medo de quebrar o pescoço com os sacos de açúcar que lhe eram arremessados em sua direção, e foi pegando o costume e o jeito com o trabalho pesado principalmente devido aos conselhos de companheiros mais velhos que trabalhavam há mais tempo na Companhia 9 .

Durante a semana era inexistente qualquer tipo de atividade recreativa ou de lazer, Luiz e seus companheiros voltavam para casa e somente jantavam e dormiam para no dia seguinte voltar

\footnotetext{
9 Pochmann (2014) argumenta que o processo de industrialização nacional ocorreu diferentemente dos países desenvolvidos, sem a consolidação de um Estado do bem estar-social e privilegiando assim a cúpula da pirâmide social brasileira, reservando a grande massa dos trabalhadores uma remuneração que ficava presa às despesas como alimentação e habitação.
} 
ao batente. Aos domingos seu único dia de folga, seu passatempo se resumia ao consumo de álcool, eventualmente algumas partidas de futebol na praia, que posteriormente fora deixado de lado devido às brigas ocasionadas pela embriaguez, e a idas a prostíbulos. Em suas próprias palavras, seu tempo de folga se resumia a "cachaça e nega".

Ele conta que devido à imaturidade e o álcool neste período não queria mais saber da mulher e do filho, não passava mais pela sua cabeça reencontrá-los e estabeleceu uma relação com uma garota de programa, apesar disso, afirma que continuava enviando todo mês dinheiro para ambos. Posteriormente Antônia, sua esposa descobriu por intermédio do primo que acolheu Luiz o relacionamento extraconjugal e então decidiu partir para Santos em busca de salvar seu casamento. Luiz estava ciente da vinda de sua família, e quando estes chegaram foram morar de favor na casa do primo de Antônia, só depois de algumas semanas que ele decidiu alugar um casebre no Morro para morar junto com a mulher e seu filho. Curiosamente a partir da chegada de sua família, a garota a qual ele tinha um relacionamento sumiu sem maiores explicações.

Luiz trabalhou por 12 anos na Companhia Usinas Nacionais, dos quais oito foram como ajudante geral e quatro operando uma das turbinas utilizadas no refino do açúcar. O salário que recebia como operador foi a melhor remuneração que teve ao longo de seu tempo de trabalho, foi nesta época em meados de 1981 e 1982 que conseguiu comprar a casa que reside até os dias de hoje e também foi quando sofreu um terrível acidente de trabalho. As turbinas operavam em uma devida temperatura, e a turbina que Luiz era responsável estava aparentemente com o termômetro quebrado. Como, segundo ele, era costume daqueles que faziam o período noturno, deu um breve cochilo e acordou com a explosão causada pelo superaquecimento da turbina. $\mathrm{O}$ espaço foi tomado pela calda de açúcar em alta temperatura e só não houve uma explosão maior porque Luiz conseguiu chegar caminhando pelo meio da calda a um duto por onde passava o açúcar e fechá-lo manualmente. Ele sofreu queimaduras de primeiro segundo e terceiro graus e ficou afastado por quase um ano do trabalho, afirma que o período que ficou recebendo pelo INSS o prejudicou quando posteriormente foi aposentar-se, uma vez que tinha que cobrir este tempo de afastamento.

Foi mandado embora junto com seus companheiros de trabalho quando a Companhia Usinas Nacionais foi fechada na cidade de Santos no ano de 1987. Por um período, trabalhou fazendo alguns serviços ocasionais na área portuária, limpando tanques de combustível até que em 1988 entrou em seu segundo emprego, o Moinho Fama, uma fábrica de processamento de grãos que era integrada nacionalmente à J.Macedo S/A. Neste emprego voltou a trabalhar como ajudante geral, 
seu salário era bem menor do que recebia como operador e também já não era possível ganhar mais fazendo horas extras, uma vez que era instituído o sistema de banco de horas.

Luiz permaneceu por 10 anos no Moinho Fama e só saiu quando fecharam as portas em 1998. No momento em que foi demitido faltavam apenas 6 meses para ele se aposentar, mas com a reforma da previdência ocorrida naquele ano este período foi para 10 anos. Ele então desistiu de procurar outro emprego, pois estava "cansado de ser burro de carga dos outros". A partir de então seguiu sustentando-se da renda da pequena quitanda que tem na cozinha de sua casa vendendo doces salgados e refrigerantes para a comunidade do Morro e do aluguel de uma segunda casa que conseguiu comprar durante o período que era operador de turbinas na Companhia Nacional. Em 2010 consegue finalmente se aposentar, como já não gastava mais com o álcool e as farras ele assegura que a modesta renda que conseguia junto com a aposentadoria era suficiente para seguir em frente.

\section{A trajetória ocupacional e o acesso à educação na segunda e terceira geração}

Antônio, filho de Luiz tem 48 anos, nascido também na cidade de Macambira veio para Santos com sua mãe conforme foi dito, no ano de 1978 aos 10 anos de idade. Sua esposa é natural de Campo do Brito, município vizinho de Macambira, se conheceram durante a adolescência no Morro do Pacheco e casaram-se quando tinham ambos 26 anos. Antônio e sua esposa têm um filho de 18 anos.

Diferente de seus pais, ambos analfabetos, Antônio teve a possibilidade de estudar. Realizou o primário na Escola Municipal Mário de Alcântara, que fica próxima ao Morro do Pacheco, durante o Ensino Colegial foi para a Escola Estadual Primo Ferreira, ainda hoje uma escola pública que é referência na região. De acordo com suas próprias palavras, estava "apto a ingressar na faculdade, mas tal feito não era possível para famílias pobres como a dele”. Conta que desde a infância trabalhou na marcenaria de seu tio até o fim de sua adolescência. La aprendeu o ofício de marceneiro, apesar de não receber nenhum tipo de salário de seu tio, sua única reclamação é o fato de não ter sido fichado na carteira de trabalho, para contabilizar este tempo na hora de sua aposentadoria. 
Logo após concluir o atual ensino médio Antônio decidiu "cair pra vida" e a procurar trabalho remunerado. Seu primeiro emprego foi como repositor de produtos em um supermercado da região aos 17 anos de idade, ficou somente por três dias, de imediato arranjou uma briga com seu encarregado, pois não queriam pagar-lhe as horas extras trabalhadas. Posteriormente trabalhou como balconista em uma avícola próxima do Morro por 3 anos. Trabalhava 8 horas diárias e recebia aproximadamente um salário mínimo e meio, o que segundo ele para um jovem solteiro e sem filhos estava de bom tamanho. Após este período Antônio começou a trabalhar como vigilante em algumas empresas do Porto, sua jornada era de 12 horas diárias e afirma que ganhava um salário bom "para uma pessoa pobre com pouco estudo". Permaneceu nesta ocupação por 3 anos, sendo mandado embora quando começaram a exigir a realização de cursos específicos para tal função.

Foi em meados de 1991, após ser demitido do posto de vigilante que Antônio começou a trabalhar como estivador no Porto de Santos, sua ocupação até os dias de hoje. Segundo ele "estivar", o trabalho de carga e descarga dos navios, era muito mais puxado quando começou do que nos dias atuais, visto que atualmente tal função conta com o auxílio de uma série de máquinas que facilitam o trabalho além de não serem mais submetidos à exposição de cargas insalubres, compostas por elementos prejudiciais à saúde.

A jornada de trabalho atual é de 6 horas podendo-se realizar no máximo 2 horas extras por dia, existindo duas modalidades de se trabalhar na estiva: contratado exclusivamente por alguma empresa do Porto, ou como avulso. Pergunto qual das modalidades é melhor na visão de Antônio, e ele me responde que apesar dos estivadores contratados gozarem de uma estabilidade muito maior, ele prefere trabalhar como avulso dado que têm o gênio forte e não tolera o comportamento abusivo dos encarregados com os companheiros que trabalham como contratados. Ele diz que têm consciência de que mais cedo ou mais tarde, por conta de sua idade, acabará tendo que ceder ao trabalho como contratado, mas que irá protelar o máximo possível.

Antônio afirma que além da estiva sempre buscou outros serviços para incrementar a renda, tendo trabalhado desde ajudante de mecânico à lavagem de tanques de combustível como fizera seu pai. Atualmente se sustenta do trabalho como estivador e do aluguel que recebe da parte debaixo da casa em que reside, comprada na época em que se casou em meados de 1994 por meio das economias que tinha realizado e a ajuda financeira de seu pai.

Pergunto sobre o que ele gosta de fazer no seu tempo livre, ele responde que sempre que possível gosta de passear com o filho e sua esposa e visitar amigos e parentes. Eventualmente bebe uma cerveja com os amigos e conta que gostava muito de beber vinho quando mais jovem, mas que 
parou de beber recentemente por conta de problemas no coração. Diferente de Luiz e de boa parte dos companheiros da estiva afirma que nunca teve maiores problemas com o álcool, questão que começou a ter maior atenção recentemente pelas próprias empresas do cais, que evitam a utilização da mão de obra de estivadores que estejam aparentemente alcoolizados devido a possíveis acidentes ocasionados por tal fato, o que era bem comum no passado.

Seu filho Bruno nunca trabalhou, concluiu o ensino fundamental e médio em escolas públicas e atualmente cursa o primeiro ano de bacharelado em ciências da computação na Universidade Santa Cecília. Antônio e sua esposa tinham o desejo que seu filho tivesse a oportunidade de se dedicar somente aos estudos, e que para concretizar tal desejo gastam quase metade de sua renda com a mensalidade da faculdade. Questiono o porquê da escolha deste curso em específico, Antônio comenta que tem um primo que realizou o mesmo curso e teve um retorno financeiro muito bom, e seu filho se espelha na trajetória deste primo. Nas palavras de Antônio, "faculdade é só pra ter o canudo, o importante é trabalhar", percepção segundo ele compartilhada também por seu filho Bruno.

Sobre como o filho passa o tempo livre, seu pai comenta que ele é um garoto muito estudioso, pacato e que gosta de jogar jogos online de computador, quando não está estudando está jogando, mal sai do seu quarto e por conta dos jogos têm amizades com pessoas do mundo todo. Uma preocupação constante de Antônio é a possibilidade do envolvimento de Bruno com o álcool, e que por isso matriculou seu filho no período matutino, o que na sua percepção diminui a possibilidade dele frequentar bares após a aula.

\section{A unidade familiar}

Em seu trabalho sobre famílias operárias na cidade de Contagem em Minas Gerais Fausto Neto (1982) define a família como:

Uma unidade social que se realiza concretamente dentro de uma situação de classe onde, do ponto de vista de seus membros, a organização e ação da família está voltada para a busca das condições de sobrevivência e, de um ponto de vista mais amplo, sua ação está voltada para a reprodução da força de trabalho em seus aspectos materiais e ideológicos (FAUSTO NETO, 1982, p.10).

A perspectiva apresentada em sua obra entende que para além de um núcleo aonde são compartilhadas vivências, relações sociais e redes de reciprocidades, a família também opera como 
núcleo fundamental na manutenção e reprodução do trabalho através da partilha de recursos econômicos advindos de seus membros, aonde se rearranjam diversas formas de ocupação. Neste sentido, não é tão somente o salário, mas o rendimento familiar que definirá entre outras coisas o seu padrão de consumo.

Outro aspecto da unidade familiar entendida por Fausto Neto (1982) é a reprodução ideológica da força de trabalho, assegurando ao longo da infância uma série de comportamentos que proporcionam uma integração adequada de seus componentes na ordem social. Essa percepção é muito similar à proposta por Bourdieu (2011) que entende a família como base de uma série de estratégias, educacionais, econômicas, matrimoniais entre outras, mas também como um ponto de partida de uma construção simbólica de mundo, inculcada desde a tenra infância. Desta maneira,

[...] a família como categoria social objetiva (estrutura estruturante), é o fundamento da família como categoria social subjetiva (estrutura estruturada), categoria mental que é base de milhares de representações e de ações (casamentos, por exemplo) que contribuem para reproduzir a categoria social objetiva. Esse é o círculo de reprodução da ordem social (BOURDIEU, 2011, p.128).

Todas estas características propostas pelos dois autores são percebidas na trajetória de Luiz e sua família. $\mathrm{O}$ vínculo existente entre ele e sua família ainda em sua terra natal, enviando dinheiro mesmo sem nutrir o desejo de reencontrá-los mostra de certa forma o peso simbólico da instituição familiar, que se faz presente mesmo na ausência de um projeto de continuidade por parte de Luiz.

Apesar deste escrito não conter as contribuições da mãe de Antônio e sua esposa pelas devidas razões já explicitadas, é a partir da realização de uma série de afazeres e da logística do lar, como cuidar dos filhos, cozinhar entre outras tantas tarefas, que assegura a manutenção da força de trabalho de Luiz e seu filho. É a partir da contribuição de suas esposas que é garantida a chegada, no dia seguinte de seus respectivos maridos aos postos de trabalho.

Outro ponto a ser considerado é o papel central que as estratégias familiares têm no momento que Luiz ao ter negada sua aposentadoria decide não mais ser explorado por ocupações que sempre exigiram muito esforço físico, abrindo assim a quitanda na cozinha de sua casa. A administração do negócio informal passa fundamentalmente pelas mãos de sua esposa Antônia.

Os esforços ao longo dos anos realizados por Luiz e sua esposa foram substanciais na possibilidade de Antônio poder prover a sua família melhores condições e oportunidades. Foi a partir da ajuda financeira de seu pai e sua mãe que ele pode adquirir a casa própria e a partir deste ponto ele e sua esposa reproduzem uma série de estratégias oriundas da geração anterior. No caso 
de Antônio e sua esposa, é ela que além de todas as tarefas do lar também lida com os inquilinos de sua casa.

Por fim, a soma de todos os esforços e estratégias explicitados até aqui contribuíram na busca de um maior acesso ao capital cultural, por parte das gerações posteriores, especialmente a terceira geração.

\section{Trabalho, família e educação}

Como a categoria de família para além do que já foi discutido, se relaciona com trabalho e educação? Como essas categorias influenciam as escolhas e estratégias produzidas pelos agentes e como estas questões se alteram de uma geração para outra?

$\mathrm{Na}$ ontologia marxista o trabalho é entendido como a mediação entre o sujeito e o objeto, em outras palavras, a ação intencional do homem sobre a natureza, que ao realiza-la transforma e rearranja a subjetividade humana, diferenciando assim a sua intervenção no mundo real da dos outros animais. O trabalho humano assinala Marx, seria essencialmente teleológico, transformando não somente a natureza a partir de sua ação, mas a própria noção de ação daquele que o realiza, assumindo assim centralidade na condição humana.

O pressuposto marxista em relação ao trabalho é presente no pensamento de Sennet (2009). Em sua obra o autor demonstra como as transformações ocorridas no mundo do trabalho durante o fim do período fordista nos Estados Unidos impactaram e transformaram as relações de uma família ítalo-americana de uma geração para outra, com relação à dinâmica familiar bem como a percepção do que é o trabalho e que culminam em um processo de corrosão de caráter, ou seja, da impossibilidade na segunda geração de construir uma narrativa em que consegue transpor para o seio familiar a ética e os valores presentes no cotidiano ocupacional.

O autor afirma que a noção de caráter é acima de tudo concentrado "a longo prazo de nossa experiência emocional" e que pode ser definido como "os traços pessoais a que damos valor em nós mesmos, e pelos quais buscamos que os outros nos valorizem" (SENNETT, 2009, p.10). Assim, o caráter é para Sennet a soma de nossas experiências de vida, e a representação simbólica destas na forma como nos projetamos para o outro. 
Boudieu não nega a importância da noção de trabalho, mas se na ontologia marxista o homem é compreendido como homo faber, para ele, aproximando-se da visão weberiana, entende o homem como homo aesteticus, um ser que constrói o real significando-o ao mesmo passo que é ressignificado por esta ação.

O habitus, esse senso prático que direciona as condutas é constituído desde a infância por meio da família e a instituição escolar. Os agentes se percebem e se diferenciam não pelo lugar que ocupam na produção ${ }^{10}$, mas pela posição que ocupam no espaço social, de acordo com um quantum de capital que possuem, no caso da sociedade moderna, cultural e econômico. O trabalho nesta perspectiva teórica, fruto do acúmulo do capital cultural e econômico, provém ou nega prestígio aos agentes, que é percebido e legitimado por todos uma vez que as estruturas de percepção como foi dito anteriormente são produto de relações sociais objetivas (BOURDIEU, 2004, 2011).

Deixando de lado a noção ontológica do trabalho, o caráter enquanto representação simbólica que se torna evidente elemento de reconhecimento e de prestígio proposto por Sennet (2009) é similar às representações que proporcionam prestígio em Bourdieu (2004, 2011).

A busca por prestígio de uma geração para outra se faz presente o tempo todo na trajetória analisada. Seja na falta no caso de Luiz, que se sente inferior devido a sua condição de analfabeto e percebida da mesma forma pelo seu filho, ou nas falas de Antônio, que denotam frustração ao afirmar que tinha a capacidade e os requisitos para ingressar em um curso superior e que não o fizera devido a sua condição financeira, e que tal frustração aparentemente se dá não somente por esta condição lhe relegar postos de trabalho inferiores e que consomem muito de sua saúde, mas também pelo simples fato de não poder ter avançado mais em seus estudos.

É perceptível como também todos os esforços atuais se voltam para que Bruno, filho de Antônio possa ter uma formação adequada. Diferente de seus pais e avós, Bruno nunca trabalhou e têm o privilégio de poder simplesmente seguir estudando, mesmo depois de ter chegado à maioridade. O fato de até o presente momento me ter sido negado por parte de Luiz e de Antônio um contato com ele, sobre o pretexto de estar sempre estudando, é a meu ver também outro indicativo de como a unidade familiar deposita em Bruno a possibilidade de alcance do prestígio via capital cultural e econômico que eles não tiveram. Outro ponto que corrobora esta tese é o fato de Antônio utilizar 50\% de sua renda familiar com as despesas com a graduação do filho.

\footnotetext{
${ }^{10}$ Bourdieu $(2004,2011)$ compreende que a existência de grupos de agentes com habitus mais ou menos homogêneos não se traduz necessariamente na existência de uma classe social coesa em si. 


\section{Considerações Finais}

Não é minha intensão afirmar que a dimensão simbólica do acesso à educação se sobrepõe ao suprimento de necessidades materiais imediatas que uma boa qualificação educacional proporciona, conseguindo melhores postos de emprego. No entanto tentei a partir das contribuições teóricas, demonstrar como estas categorias, o simbólico e o objetivo se relacionam e influenciam na formação de estratégias e escolhas da trajetória familiar apresentada, não sendo assim categorias antagônicas, mas complementares entre si.

Além das estratégias familiares, outro fator não menos importante que possibilitou a Luiz desistir de trabalhar formalmente, esperar a aposentadoria e permitir a Antônio trabalhar somente como estivador e ainda sim bancar os estudos de seu filho sem que ele precise de uma segunda ocupação é o local em que habitam. O custo de vida e da habitação no Morro do Pacheco é extremamente baixo, principalmente quando comparado ao resto da cidade de Santos. Dificilmente Luiz e sua família conseguiriam reproduzir tais condições e possibilidades se habitassem outro bairro, mesmo sendo periférico.

Por fim, fica muito claro a partir deste estudo de caso o avanço no acesso a educação nas gerações seguintes. Apesar disso me parece dúbia nesta trajetória a hipótese de que as escolhas educacionais estão ao mesmo tempo subordinadas a uma necessidade de rápida inserção no mercado de trabalho formal. Embora no discurso de Bruno, apresentado por intermédio de seu pai, a escolha do curso de graduação se deu pensando nos possíveis postos de trabalho, a graduação em ciências da computação difere das escolhas presentes nas terceiras gerações de outras famílias que não tiveram seus relatos expostos neste trabalho, onde a grande maioria optou por cursos tecnólogos, com uma duração muito menor e inserção muito mais rápida.

\section{Referências}

BOURDIEU, Pierre. Coisas ditas. São Paulo. Ed. Brasiliense, 2004.

Pierre. "Esboço de uma teoria da prática". In. ORTIZ, Renato (Org.). Pierre

Bourdieu: sociologia. São Paulo. Ed. Ática, 1983. 
, Pierre. Razões práticas: Sobre a teoria da ação. Campinas, SP. Ed. Papirus, 2011.

FAUSTO NETO e QUIROGA, Ana M. Família operária e reprodução da força de trabalho. Petrópolis, RJ. Ed. Vozes, 1982.

MENEZES, Marilda. Da Paraíba prá São Paulo e de São Paulo prá Paraíba: Migração, família e reprodução da força de trabalho. Tese de mestrado, defendida na Universidade Federal da Paraíba. Campina Grande, PB, 1985.

PAIS, José. M. Nos Rastros da Solidão. Deambulações Sociológicas. $2^{\mathrm{a}}$ Edição. Âmbar. Lisboa, 2006.

PIMENTA, Marcus. A. (edit). Caminhos do Mar: memórias do comércio da Baixada Santista. Museu da Pessoa, São Paulo. 2002.

POCHMANN, Marcio. O mito da grande classe média: capitalismo e estrutura social. São Paulo. Ed. Boitempo, 2014.

ROCHA-TRINDADE, Maria B. Sociologia das Migrações. Edição/reimpressão. Ed. Universidade Aberta, 1995.

SANTOS, André da R. "O processo histórico de ocupação no município de Santos: a expansão a partir do Centro". In. VAZQUEZ, Daniel A. (Org.). A questão urbana na Baixada Santista: Políticas, vulnerabilidades e desafios para o desenvolvimento. Ed. Universitária Leopoldianum. São Paulo, 2011.

SAYAD. Abdelmaleck. A Imigração ou os Paradoxos da Alteridade. EDUSP. São Paulo, 1998.

SENNETT, Richard. A Corrosão do Caráter: As Consequências Pessoais do Trabalho no Novo Capitalismo. 14 a edição. Ed. Record. Rio de Janeiro, 2009. 


\title{
HAPPY THAT GETS A GOOD JOB: GENERATIONAL TRAJECTORIES AT WORK AND EDUCATION FAMILIES OF SERGIPANAS FAMILIES IN SANTOS
}

\begin{abstract}
Having the port as an important economic activity and crucial stage of the arrival of large numbers of immigrants in Brazil at the beginning of the last century, the city of Santos has the phenomenon of migration as an element inherent in its history. Among the most varied origins that make up the population of Santos, there is the massive presence of northeastern migrants from the state of Sergipe. Research on development from which this article is an offshoot, has the general objective to investigate the changes in occupational trajectories and education of migrants from the state of Sergipe residents in the city of Santos. I propose from the trajectory of a family Sergipeans migrants composed of three generations a reflection on the migratory flow between Santos and Sergipe municipality of Macambira. Subsequently seek to understand through reports and theoretical contribution of Pierre Bourdieu, Richard Sennett among others, the categories work and education change, related or not, from one generation to another and what the role of the family unit in this process..
\end{abstract}

Key-words: Migration. Generational trajectories. Education. Job. 